\title{
Tunica Vaginalis
}

National Cancer Institute

\section{Source}

National Cancer Institute. Tunica Vaginalis. NCI Thesaurus. Code C33822.

Serous membrane that covers the testicles. 